\title{
Interprofessional Care and Role of Team Leaders
}

\author{
Bachchu Kailash Kaini ${ }^{1}$ \\ 'Queen Elizabeth Hospital, Stadium Road, Woolwich, London, SE 18 4QH, UK.
}

ABSTRACT

Interprofessional care is an essential part of the health service delivery system. It helps to achieve improved care and to deliver the optimal and desired health outcomes by working together, sharing and learning skills. Health care organisation is a collective sum of many leaders and followers. Successful delivery of interprofessional care relies on the contribution of interprofessional care team leaders and health care professionals from all groups. The role of the interprofessional care team leader is vital to ensuring continuity and consistency of care and to mobilise and motivate health care professionals for the effective delivery of health services. Medical professionals usually lead interprofessional care teams. Interprofessional care leaders require various skills and competencies for the successful delivery of interprofessional care.

Keywords: interprofessional care; team leaders; roles; competencies

\section{INTRODUCTION}

Health care is a unique service industry mixed with various factors such as personal and social needs; and involvement of public, private and voluntary sectors. Health care professionals are the biggest resources in health care delivery system as it is a labour intensive service industry. The complex nature of health care and development of very specific expertise within all medical, nursing and allied health care professionals means that no single professional can deliver a complete package of health care. Therefore, interprofessional care comes in picture and interprofessional care team leaders play vital roles for the delivery of successful interprofessional care.

\section{Interprofessional Care}

Interprofessional working occurs within the team of health care professionals, between the team and outside the team. ${ }^{1}$ An interprofessional care team works towards a co-ordinated division of labour and provide holistic and integrated care. $^{2}$ The main objective of interprofessional care team is to deliver interdisciplinary client care. Interprofessional care team consult, confer, and co-operate formally and deliberately over a considerable period of time.

Interprofessional care behaviours apply in any organisations or situation where health care professionals interact to achieve shared goals for effective delivery of health care. Interprofessional care behaviours involve co-operating in the patient focused delivery of care; co-ordinating one's care with other health care professionals so that gaps, issues and errors are avoided; and collaborating with others through shared problem solving and shared decision making, especially in circumstances of uncertainty. ${ }^{3}$ These processes reflect high levels of interdependence among health care professionals and those embedded in

Correspondence: Bachchu Kailash Kaini, Queen Elizabeth Hospital, Stadium Road, Woolwich, London, SE18 4QH, UK. Email: bkaini@nhs.net, Phone: +44-7988617040. 
health care teams in any health care organisations like hospitals or in and between health care organisations.

\section{Benefits Of Interprofessional Working}

A single health care professional or groups or professionals working in an un-coordinated way cannot achieve the aim of effective delivery of health services. Health care professionals expect coherent, effective and accessible services for the effective delivery of health care. Ovretveit and colleagues ${ }^{1}$ state that interprofessional working is the best way of working in health care organisations to deliver effective health services to service users. Literature confirm that there is a direct correlation between successful interprofessional care team and quantifiable service improvements in patient safety and quality of delivery of health. ${ }^{4-8}$

Empirical researches have demonstrated that more positive health care outcomes are achieved by collaborating interprofessional teams. ${ }^{9-20}$ In order to improve the quality of health services, health care professionals are required to follow an interprofessional working approach. Interprofessional working is a way of consistently providing benefits for service users, health care professionals and health organisations. ${ }^{1}$

\section{Team Leaders for Interprofessional Care}

Strong leaders in interprofessional care team satisfy interprofessional team members, service users and community needs, and they value all team members' potential contributions in meeting those needs and achieving shared goals and optimal desired outcomes. ${ }^{3}$ An interprofessional care team leader interacts with team members in ways that draw out potential contributions and build support for working together through an understanding of the team dynamics. ${ }^{21}$

As interprofessional care team leaders highlight the importance of collaborative practice by working together among themselves, communicating and implementing the shared values related to interprofessional care teamwork, health care professionals are more likely to be inspired to seek and provide help. ${ }^{22}$ Therefore, it is evident that leaders of interprofessional care team play important roles to achieve common goals, to guide team members and to ensure that all members of interprofessional care team actively participate in the care delivery process.

It is important that the team members obligate a sense of loyalty to their leaders ${ }^{23}$ and they accept the blame when something goes wrong and pass praise for success on to their team. ${ }^{24}$ Commitment from the executive level, top management; team leaders; and team member's commitment to value and respect teamwork are equally vital to achieve an interprofessional team's desired outcome. The responsibilities of the organisation's leadership to the team are the focus on the accomplishment of goals and desired outcome.

\section{Roles of Interprofessional Care Team Leaders}

The role of the interprofessional care team leader is crucial to ensuring continuity and consistency of care for the effective delivery of health services. The interprofessional care team leader also plays a coordinating role to plan, asses, manage and deliver the health care for service users. Therefore, it is obvious that the role of the interprofessional care team leader is best lead and managed by health care professionals with lot of experience with clinical specialties related to problems of service users.

A health care professional with a particular skill, interest or expertise in a particular case should take the leadership roles. Leadership is a part of interprofessional care and interprofessional care teams are lead by clinical leaders. ${ }^{6}$ Usually the most senior medical professionals in the team take the leadership roles and responsibilities for interprofessional care. It is a common and accepted practice in health care sector. The authority that medical professionals get through the licensing process gives them the power, privilege and exclusive rights. Medical professionals were perceived to hold more recognition and power in health care teams due to access, the perception that work must be adjusted to their requirements.

Interprofessional care team leaders play task and relationship oriented leadership roles for interprofessional working. In the task oriented roles, the leader of the health care team helps other team members to perform tasks effectively so that the health care team can achieve shared goals and optimal desired outcomes. Whereas in the relationship oriented leadership roles, the leader of the interprofessional care team assisted health care professionals to work together more effectively.

The $\mathrm{ClHC}^{25}$ also focuses on these two components (task and relationship oriented) of interprofessional care leadership and further asserts that there may be two leaders, one for health care professionals to keep the work flowing and the other who connects with service users in a helping relationship, serving as the link between the team and the service users. Health care professionals play mainly three roles related to interprofessional working - communicator, co-ordinator and facilitator. Apart from these roles, senior medical professionals also play active roles of educator and 
Kaini et al. Interprofessional Care and Role of Team Leaders

leader.

The role of interprofessional care team leader is played differently within and across the health care organisations and it is affected by various factors such as organisational structures, practices, policies and protocols. Interprofessional care team leader should be able to encourage team members to follow their leader, nurture team members, support relationships in the team, see the work of the team as a model or pattern and plan for the future. Interprofessional working is more based on professional skills, knowledge and expertise than roles and responsibilities assigned by the clinical leader or organisation. ${ }^{26}$

\section{Skill And Competencies Of Interprofessional Care Team Leaders}

Interprofessional care team leaders need to have various skills and competencies such as communication, interpersonal skills, flexibility and creative problem solving to drive their team effectively and to achieve desired team goals. Commitment to the team, ability to support and motivate team members, desire to take responsibility, willingness to unite team members and ability to lead by an example are some of the features of team leadership. ${ }^{21}$ Moreover, Zaccaro and colleagues ${ }^{21}$ argue that an ability to communicate information to peers and followers in the interprofessional care team is one of the major criteria of success.

The British Medical Association ${ }^{27}$ suggests that that 'medical school is a good place to begin to learn about the importance of collaborative team working'. It highlights that clinical leaders should be able to perform within a team and should be capable of taking personal responsibility for the decisions they made and be accountable for their functions. According to the NHS Leadership Academy, ${ }^{28}$ clinicians need to show leadership by working with others in teams and networks to deliver and improve services by demonstrating the following competence:

\section{- Developing networks \\ - Building and maintaining relationships \\ - Encouraging contribution \\ - Working within teams}

Interprofessional care competencies can be 'described, taught, practised and assessed and all health care professionals and their leaders have a shared responsibility' to advance interprofessional care competencies. ${ }^{29}$ Continuous professional and skill development for interprofessional care team leaders in interpersonal and interprofessional areas such as communication, change management, teamwork and leadership is important to the successful operation of interprofessional care team. ${ }^{18}$

Characteristics of health care leaders are explained in terms of various attributes, such as roles, visions, and strategies; while health care managers are associated with responsibilities defined in relation to their position defined in the management structures. ${ }^{30}$ A leader of an interprofessional care team is only successful if the team members are empowered. ${ }^{31}$ Personal strengths of an interprofessional care team leader combined with organisational strengths sum up the credibility and strengths to interprofessional care team.

\section{Changing Context}

Interprofessional working in health care is an evolving and negotiated process which is facilitated by supportive leadership by creating a right structure for interprofessional care. ${ }^{13}$ The King's Fund's report ${ }^{32}$ 'The future of leadership and management in the NHS: No more heroes' recognises that the type of leadership the NHS requires is changing. It further suggests that the model of shared leadership should be adapted for the effective delivery of health service and this requires a focus 'on the development of organisations and the teams, not just individuals, on leadership across systems of care rather than just institutions, and on followership as well as leadership. The report also suggests that 'health service leaders help to promote professional cultures that 'support teamwork, continuous improvement and patient engagement'.

An interprofessional care team may have many leaders depending on the nature and features of the team. Health care teams rarely have a single leader and the leadership role is usually assigned to the most senior member of staff with high status professions or the leader may emerge based on service users' need and the situation of services. ${ }^{33}$ Sullivan ${ }^{34}$ asserts that health care professionals who are leaders in one or more activities are also followers in other activities. Health care organisation is a collective sum of many leaders and followers and clinical and non-clinical activities. Health care professionals should realise the existence of many leaders in their organisations.

Creating leadership roles within the health care team may change the power structures and authority roles of health care professionals. Duncanis and Golin ${ }^{35}$ assert that leadership of the health care team and distribution of power may shift due to the changing nature of the clinical, administrative and managerial task.

Health care professionals face many challenges on a daily basis. It is not the case that health care professionals 
have an opportunity to work with others. Sometimes they work in isolation and sometimes they join hands with other health care professionals. The successful interprofessional working depends upon many factors, some can be in control of health care professionals and others may not be in their control.

\section{THE WAY FORWARD}

Institutionalising an interprofessional care team leadership culture is one of the vital aspects of leadership. Interprofessional care team leaders not only focus on the desired outcome itself but also on the relationship of each team member to the work. They have a greater responsibility to evaluate and critique the performance of tasks of health care professionals and the accomplishment of shared goals and outcomes.
Interprofessional care team leaders should have an open and positive attitude for assessing and critiquing their performance. ${ }^{36}$ Capability to lead the interprofessional care team, power and ability to make decisions, and overall charisma of the leader influence the overall performance and outcome of the team. ${ }^{37}$ Therefore, today's health care leaders should be fit for the current context of health care delivery system. Moreover, they should be ready for the future by enhancing their skills and building capacity in order to meet expectations of their fellow members and colleagues.

To conclude, leadership plays vital roles at all levels of the health care system for effective implementation of interprofessional care agenda in health care organisations. Effective interprofessional care can be achieved when all the levels within the health care system work together under the dynamic leadership.

\section{REFERENCES}

1. Ovretveit J, Mathias $\mathrm{P}$, Thompson T. Interprofessional Working for health and social care. Hampshire: Macmillan; 1997.

2. Hornby S, Atkins J. Collaborative Care: Interprofessional, Interagency and Interpersonal. Oxford: Blackwell Publishing; 2000.

3. Interprofessional Education Collaborative. Core Competencies for Interprofessional Collaborative Practice: Report for an Expert Panel [Online]. [cited 2014 Sep 04]; Available from: URL:http://www.aacn.nche.edu/ education-resources/ipecreport.pdf

4. Department of Health. The NHS Next Stage Review: High Quality Care for All. London: HMS; 2008.

5. Department of Health. Equity and Excellence: Liberating the talents. London: HSMO; 2010.

6. Health Canada. Primary Health Care - A Framework that Fits: The language of interprofessional collaboration [Online]. [cited 2014 Sep 04]; Available from: URL:http:// www.eicp.ca/en/resources/language/definitions.asp

7. Institute of Medicine. Allied Health Workforce and Services - Workshop Summary [Online]. [cited 2014 Sep 04]; Available from: URL:http://www.iom.edu/ Reports/2011/Allied-Health-Workforce-and-Services. aspx?utm_medium=etmailandutm_source $=$ Institute $\% 20$ of $\% 20$ Medicineandutm_campaign $=12.08 .11+$ Report + + Allied + Health + Workforceandutm_content $=$ New $\% 20$ Reportsandutm_term=Non-profit $/$

8. Joint Commission on the Accreditation of Health Care Organisations. Accreditation [Online]. [cited 2014 Sep 04]; Available from: URL:http://www.jointcommission.org/ accreditation/accreditation_main.aspx
9. Pollard K, Sellman D, Senior B. The need for interprofessional working. In: Barrett G, Sellman D, Thomas J (eds.) Interprofessional working in health and social care. Hampshire: Palgrave; 2005. p. 7-17.

10. Dow L, Evans N. Medicine. In: Barrett G, Sellman D, Thomas $\mathrm{J}$ (eds.) Interprofessional working in health and social care. Hampshire: Palgrave; 2005. p. 64-73.

11. Ritter HA. Collaborative practice: what's in it for medicine? Nursing Administration quarterly 1983; 7:31-6.

12. Biggs S. Interprofessional collaboration: problems and prospects, In: Ovretveit J, Mathias P, Thompson, T (eds.) Interprofessional working for health and social care. Hampshire: Macmillan; 1997. p. 186 - 200.

13. Miller $C$, Freeman $M$, Ross N. Interprofessional practice in health and social care: Challenging the shared learning agenda. London: Arnold; 2001.

14. Leathard A. Interprofessional Collaboration: From Policy to Practice in Health and Social Care. East Sussex: Routledge; 2003.

15. Canadian Health Services Research Foundation. Teamwork in Health Care: Promoting effective teamwork in health care in Canada. CHSRF [Online]. [cited 2014 Sep 04]; Available from: URL:http://www.chsrf.ca/Migrated/ PDF/ResearchReports / CommissionedResearch/ teamwork-synthesis-report_e.pdf

16. Nolte J. Enhancing interdisciplinary collaboration in primary health care in Canada. Ottawa: Enhancing Interdisciplinary Collaboration in Primary Health Care Initiative [Online]. [cited 2014 Sep 05]; Available from: URL:http://www. eicp.ca/en/resources/pdfs/enhancing-interdisciplinarycollaboration-in-primary-health-care-in-canada.pdf 
17. Byrnes V, Chapman C, O'Riordan A, Schroder C. Collaborative Practice Assessment Tool (CPAT): Developing educational strategies to enhance interprofessional collaborative practice (Paper presented at Health Sciences Education Rounds). Kingston: Office of Interprofessional Education and Practice, Queen's University; 2009.

18. Enhancing Interdisciplinary Collaboration in Primary Health Care. The principles and framework for interdisciplinary collaboration in primary health care. Ottawa: EICP [Online] [cited 2014 Sep 04]; Available from: URL:http://www. eicp.ca/en/principles/sept/EICP-Principles \%20and $\% 20$ Framework\%20Sept.pdf

19. Holland R, Battersby J, Harvey I, Lanaghan E, Smith J, Hay I. Systematic review of Multidisciplinary interventions in heart failure. Heart. 2005;91:899-906.

20. McAlister FA, Stewart S, Ferrua S, McMurray JJ. Multidisciplinary strategies for the management of heart failure patients at high risk for admission. Journal of the American College of Cardiology. 2004;44(4):810-19.

21. Zaccaro SJ, Heinen B, Shuffler M. Team leadership and team effectiveness. In: Salas E, Goodwin GF, Burke CS (eds.) Team effectiveness in complex organizations. New York: Psychology Press; 2009. p. 83-111.

22. Crowley S, Wollner I. Collaborative practice: A tool for change. Oncology Nurse Forum. 1987;14(4):59-63.

23. Engel C. A functional anatomy of teamwork. In: Leathard A.(ed.) Going Interprofessional - working together for health and welfare, East Essex: Brunner-Routledge; 1994. p. 64-74.

24. Jones A, Jones D. Improving teamwork, trust and safety: An ethnographic study of an interprofessional initiative. Journal of Interprofessional Care. 2011; 25(3):175-181.

25. Canadian Interprofessional Health Collaborative. A National Interprofessional Competency Framework. Vancouver: CIHC [Online]. [cited 2014 Sep 04]; Available from: URL: http://www.cihc.ca/files/CIHC_IPCompetencies_Feb1210. $\mathrm{pdf}$

26. Zwarenstein M1, Goldman J, Reeves S. Interprofessional collaboration: effects of practice-based interventions on professional practice and healthcare outcomes. Cochrane Database Syst Rev. 2009 Jul 8;(3):CD000072.
27. British Medical Association. Doctors' perspectives on clinical leadership. London: British Medical Association; 2012.

28. NHS Leadership Academy. NHS Leadership Competency. Coventry: NHS Institution for Innovation and Improvement; 2011.

29. Oandasan I, Robinson J. Final report of the interprofessional care strategic implementation committee. Toronto: Interprofessional Care Core Competency Working Group [Online]. [cited 2014 Sep 04]; Available from: URL:http:// www.healthforceontario.ca/upload/en/whatishfo/ ipcproject/ccwg\%20final\%20report\%20_nov\%2020\%20-\%20 final\%202010_.pdf

30. Willumsen E. Leadership in interprofessional collaboration the case of childcare in Norway. Journal of Interprofessional Care 2006; 20(4): 403-413.

31. McWilliam CL, Coleman S, Melito C, Sweetland D, Saidak J. Smit J, Thompson T, Milak,, G. Building empowering partnerships for interprofessional care. Journal of Interprofessional Care 2003;17(4):363-376.

32. The King's Fund. The future of leadership and management in the NHS: No more heroes. London: The Kings Fund; 2011.

33. Hammick M, Freeth D, Copperman J, Goodsman D. Being Interprofessional. Cambridge: Polity; 2009.

34. Sullivan TJ. Collaboration: A Health Care Imperative. New York: McGraw-Hill; 1998.

35. Duncanis AJ, Golin AK. The Interdisciplinary Health Care Team: A Handbook. Maryland: Aspen Systems Corporation; 1979.

36. O'Leary KJ, Haviley C, Slade M, Shah H, Lee J, Williams M. Improving teamwork: Impact of structured interdisciplinary rounds on a hospitalist unit. Journal of Hospital Medicine 2010;1-4.

37. Sorber ME, Farley DO, Mattke S, Lovejoy S. Outcome measures for effective teamwork in inpatient care. CA: RAND [Online]. [cited 2014 Sep 04]; Available from: URL:http://www.rand.org/pubs/technical_reports/2008/ RAND_TR462.sum.pdf 